\title{
Variability in gustatory quality identification
}

\author{
HERBERT L. MEISELMAN AND ERNEST DZENDOLET
}

UNIVERSITY OF MASSACHUSETTS

A total of 60 male and 60 female non-smoking undergraduates were tested on two gustatory screening tasks in which solutions representing the four basic taste qualities were used. The solution concentrations chosen were low, but supposedly distinct as to their qualities. Only $16 \%$ of the males were able to identify all solutions correctly, i.e., to a criterion of 4 correct out of 7 presentations, as compared to $34 \%$ of the females. A further $28 \%$ of the males consistently confused the sour and bitter qualities as did $10 \%$ of the females. A correction procedure used in one part of the experiment did not prevent this confusion. We suggest that the sour-bitter confusion may be the gustatory analogue of abnormal color vision.

Experimental awareness of relatively common insensitivities and deficits in Ss to visual and auditory stimuli has resulted in the general use of some form of screening task or procedure for Ss used in experiments with these modalities. The possibility that such a procedure may also be necessary in gustation has generally been overlooked, although Pilgrim (1961) reported a suspected confusion between salty reports, with $\mathrm{NaCl}$ as the stimulus, and bitter reports, with caffeine as the stimulus, in an experiment requiring a magnitude scaling of mixtures of qualities. He also reported that naming the qualities of pure samples of his stimuli before the experiment did not affect his Ss' performance. Pangborn (1961) suggested that a confusion between sour and bitter was common, but she cited no data to support her statement. Perhaps the only recent experiment to screen Ss was one by Dzendolet and Meiselman (1967) who found that only four out of 23 nonsmoking students met a criterion for correctly naming the four basic qualities, i.e., bitter, salty, sour, and sweet, in four screening solutions which were near absolute threshold. The fact that only four Ss were successful may be partly related to the fact that the solutions were near threshold. Fischer, Griffin, and Rockey (1966) found that compounds could be divided into two types, those which showed a normal or Gaussian distribution of thresholds, as obtained by their double-blind placebo procedure, when many Ss were tested, and those compounds which showed a bimodal distribution. The so-called Gaussian compounds included $\mathrm{NaCl}$, $\mathrm{HCl}$, sucrose, and quinine. The bimodal type was typified by 6-n-propyl thiouracil. Ss having a high or low threshold for one Gaussian compound tended to have a similar threshold for another Gaussian compound, except for $\mathrm{HCl}$. There was little correlation between the threshold for another Gaussian compound and the threshold for $\mathrm{HCl}$. It may have been that if the concentration in the Dzendolet and Meiselman experiment had been higher, more Ss would have reached the criterion for correct responding.

It is especially important currently that all Ss in gustatory experiments concerned with quality be drawn from the same population of quality-responders because of the present disagreements as to the coding mechanism for qualities. Possible additional confusion of the issue because of variability in Ss would not be desirable. This paper will present evidence for the necessity of a screening procedure, and will suggest one to use.

\section{EXPERIMENT 1}

\section{Subjects}

Ss for the first experiment were 40 male and 40 female undergraduates at this University. They were non-smokers, and were not taking any medication at this time. Participation in the experiment was in partial fulfillment of a requirement for an introductory psychology course.

\section{Stimuli}

The solutions used as the screening task of this experiment were: $0.002 \mathrm{M} \mathrm{HCl}, 0.050 \mathrm{M} \mathrm{NaCl}, 0.020 \mathrm{M}$ $\mathrm{KCl}$, and $0.015 \mathrm{M}$ sucrose to represent the sour, salty, bitter, and sweet qualities, respectively. The solutions were made with reagent grade chemicals, except that the sucrose was table sugar, and locally available distilled water. The concentrations of $\mathrm{HCl}, \mathrm{NaCl}$, and sucrose were chosen to permit recognition of their respective qualities (Pfaffmann, 1959, Tables 2, 4, 6), and that of $\mathrm{KCl}$, to represent bitter, was based on the results of an earlier experiment (Dzendolet \& Meiselman, 1967). The solutions were kept in a water bath at $35^{\circ} \mathrm{C}$.

\section{Procedure}

$S$ was blindfolded upon entering the experimental room, and seated before a sink. He was instructed to sip all of a solution presented to him $(10 \mathrm{ml})$ in a $50 \mathrm{ml}$ beaker. He was to hold the solution in his mouth for about $3 \mathrm{sec}$, and then to spit it into the sink. At this point, $S$ was to report the gustatory quality, but his responses were limited to bitter, salty, sour, sweet, or no taste. Each of the four screening solutions was presented seven times, with the order of 28 solutions being random except that no solution was presented more than twice in succession. No rinse was used between presentations, but $S$ could spit as much as he wanted after the presentation. The rationale for not using a rinse to speed the tongue's 
Tahle 1. Percentages of quality responses to four screening solutions. (Experiment 1)

\begin{tabular}{llrrrrr} 
Subjects & Solutions & \multicolumn{5}{c}{ Qualities } \\
& & saur & solty & bitter & sweet & no taste \\
\hline \multirow{3}{*}{ Females } & $\mathrm{HCl}$ & 57.5 & 5.4 & 28.2 & 7.8 & 1.1 \\
$(\mathrm{~N}=40)$ & $\mathrm{NaCl}$ & 3.9 & 86.4 & 5.0 & 2.9 & 1.8 \\
& $\mathrm{KCl}$ & 15.0 & 5.4 & 62.8 & 4.3 & 12.5 \\
& Sucrose & 11.4 & 2.9 & 14.6 & 45.4 & 25.7 \\
& $\mathrm{HCl}$ & 42.9 & 10.0 & 28.6 & 13.2 & 5.3 \\
Males & $\mathrm{NaCl}$ & 7.9 & 82.1 & 8.6 & 0.3 & 1.1 \\
$(\mathrm{~N}=40)$ & $\mathrm{KCl}$ & 19.6 & 3.7 & 49.6 & 10.0 & 17.1 \\
& Sucrose & 9.3 & 4.3 & 10.7 & 52.1 & 23.6 \\
\hline
\end{tabular}

recovery from adaptation to the stimulus was based primarily on the fact that the rinse also would introduce a new stimulus into the experiment. If ordinary tap water were used, the composition of this new stimulus would be unknown and generally very variable, certainly from laboratory to laboratory. Distilled water would be equally inadvisable because of its deleterious effects on living cells. In effect, saliva was used as the rinse. McBurney \& Pfaffmann (1963) had concluded earlier that the use of a rinse would introduce a number of uncontrolled variables which would affect the adaptation level in an unknown and variable manner. Békésy (1966) had also pointed out that the use of water did not seem to give as reliable results as not using a rinse.

Time between presentations was from 90 to $120 \mathrm{sec}$. There is no generally accepted rest interval in this type of experiment. For example, the interval has ranged from $15 \mathrm{sec}$ (McBurney \& Pfaffmann, 1963) to $10 \mathrm{~min}$ (Békésy, 1966).

\section{Results}

In order to separate correct from incorrect responding, a criterion was adopted. If $\mathbf{S}$ reported four or more correct quality responses out of seven presentations of a particular stimulus, he was classified as a sensitive taster of that quality. The results were that nine males and 15 females reached or exceeded this criterion for all four solutions. Ten males and 13 females fell below the criterion to only one of the stimuli. Sixteen males and $11 \mathrm{fe}-$ males fell below criterion to two of the solutions. Five males and no females fell below criterion to three of the solutions, and no males and one female fell below criterion to all four solutions. It is clear on the basis of this task and this criterion that only $22.5 \%$ of the males, and $37.5 \%$ of the females would qualify as sensitive tasters.

The percentages of the different qualities reported to the various stimuli are given in Table 1. The five possible responses were not equally frequent, and the reason may have been that the relative sensation magnitudes of some solutions were somewhat higher than the others. A second experiment was undertaken with some different solutions to attempt to evoke the same percentage of responses to all the solutions.

\section{EXPERIMENT 2}

\section{Subjects}

Additional new Ss, 20 males and 20 females, were selected according to the same criterion used earlier.

\section{Stimuli}

The $0.002 \mathrm{M} \mathrm{HCl}$ was retained, the $\mathrm{NaCl}$ was reduced to $0.040 \mathrm{M}$, the sucrose was raised to $0.025 \mathrm{M}$, and the $\mathrm{KCl}$ was replaced by $0.000008 \mathrm{M}$ quinine sulfate.

\section{Procedure}

Half of the Ss, 10 males and 10 females, were randomly selected and tested as in the earlier experiment. The other half were tested according to a "correction procedure," because the earlier data suggested that some Ss may have been transposing some quality names, e.g., calling $\mathrm{HCl}$ bitter, and $\mathrm{KCl}$ sour. The correction procedure was an attempt to see if such transpositions may have been a naming problem. In this procedure, the four different solutions were presented on the first four trials. After the first solution, $S$ was told how the average $S$ would have responded, but it was emphasized that $S$ should report his own opinion in each case. After the first four solutions, no further correction was supplied, and the order of the remaining solutions was randomized. The first response to each of the four solutions in the correction and non-correction procedures was not used in the analysis of the quality responses.

\section{Results}

The criterion for a sensitive responder was set at four out of six correct responses. The results were that one male and three females reached this criterion in the non-correction group for all the solutions, and two males and five females in the correction group. The frequency of naming of the four quality responses was more nearly equal in this experiment, although the relative frequency of the no-taste responses remained about the same. An analysis of variance was carried out on the percentage of correct responses in order to assess the effects and interactions of the following variables: Sex (male vs female), Instructions (correction vs non-correction), Compounds, and Trials (presentations $2-4$ vs $5-7$ ). The only significant effect was that of Compounds ( $F=$ 10.62, $\mathrm{df}=3 / 108, \mathrm{p}<.001$ ). The form of this effect was a lower percentage of correct responses to quinine sulfate. Inspection of Table 2 shows that there was a tendency for the correct responses to increase somewhat with the correction procedure, except for the bitter responses to quinine sulfate. These decreased, and the change was reflected in an increase of sour responses to the quinine solution.

\section{GENERAL DISCUSSION}

The overall results indicate that the occurrence of females in the college population who are sensitive and correct responders to gustatory qualities is $34 \%$ and 
Table 2. Percentages of quality responses to four screening solutions, with information given initially as to the quality present (correction procedure), and with no information (non-correction).

(Experiment 2)

\begin{tabular}{|c|c|c|c|c|c|c|c|}
\hline Subjects & Procodure & Solutions & sour & solty & $\begin{array}{l}\text { Qualities } \\
\text { bitter }\end{array}$ & swoet & no taste \\
\hline $\begin{array}{l}\text { Females } \\
(N=10)\end{array}$ & Non-correction & $\begin{array}{l}\mathrm{HCl} \\
\mathrm{NoCl} \\
\text { Quinine } \\
\text { Sucrose }\end{array}$ & $\begin{array}{r}56.7 \\
5.0 \\
5.0 \\
5.0\end{array}$ & $\begin{array}{c}8.3 \\
76.7 \\
0 \\
0\end{array}$ & $\begin{array}{r}33.3 \\
6.6 \\
63.3 \\
11.7\end{array}$ & $\begin{array}{c}0 \\
0 \\
5.0 \\
75.0\end{array}$ & $\begin{array}{r}1.7 \\
11.7 \\
26.7 \\
8.3\end{array}$ \\
\hline $\begin{array}{l}\text { Females } \\
(\mathrm{N}=10)\end{array}$ & Correction & $\begin{array}{l}\mathrm{HCl} \\
\mathrm{NaCl} \\
\text { Quinine } \\
\text { Sucrose }\end{array}$ & $\begin{array}{r}66.7 \\
1.7 \\
18.3 \\
3.4\end{array}$ & $\begin{array}{c}1.7 \\
83.3 \\
0 \\
0\end{array}$ & $\begin{array}{r}28.3 \\
5.0 \\
55.0 \\
8.3\end{array}$ & $\begin{array}{r}3.3 \\
3.3 \\
5.0 \\
88.3\end{array}$ & $\begin{array}{c}0 \\
6.7 \\
21.7 \\
0\end{array}$ \\
\hline $\begin{array}{l}\text { Males } \\
(N=10)\end{array}$ & Non-correction & $\begin{array}{l}\mathrm{HCl} \\
\mathrm{NaCl} \\
\text { Quinine } \\
\text { Sucrose }\end{array}$ & $\begin{array}{r}43.3 \\
6.7 \\
10.0 \\
5.0\end{array}$ & $\begin{array}{c}5.0 \\
65.0 \\
10.0 \\
0\end{array}$ & $\begin{array}{r}36.7 \\
16.7 \\
43.3 \\
1.7\end{array}$ & $\begin{array}{r}15.0 \\
1.6 \\
1.7 \\
80.0\end{array}$ & $\begin{array}{c}0 \\
10.0 \\
35.0 \\
13.3\end{array}$ \\
\hline $\begin{array}{l}\text { Moles } \\
(N=10)\end{array}$ & Correction & $\begin{array}{l}\mathrm{HCl} \\
\mathrm{NaCl} \\
\text { Quinine } \\
\text { Sucrose }\end{array}$ & $\begin{array}{c}60.0 \\
10.0 \\
23.3 \\
1.7\end{array}$ & $\begin{array}{c}1.6 \\
76.7 \\
0 \\
1.7\end{array}$ & $\begin{array}{r}36.7 \\
6.7 \\
35.0 \\
1.7\end{array}$ & $\begin{array}{r}1.7 \\
5.0 \\
13.4 \\
93.2\end{array}$ & $\begin{array}{r}0 \\
1.6 \\
28.3 \\
1.7\end{array}$ \\
\hline
\end{tabular}

the occurrence of males is 16\%. A correction procecure can increase the occurrence of these responders to some degree, but with some peculiar effect on the bitter response, so that this procedure is not recommended without further investigation.

The most frequent difficulty of these Ss appeared to be a confusion between sour and bitter as menthoned briefly by Pangborn (1961). In the first experiment in which $\mathrm{KCl}$ was the stimulus for bitter, five females and 12 males made the sour-bitter confusion. In the second experiment, no females in the noncorrection procedure made this confusion, although three did in the correction procedure. The number of corresponding males were two and four, respectively. If the correction procedure is disregarded, this means that $10 \%$ of the females made the sourbitter confusion, and $28 \%$ of the males. The confuston can also be seen in Table 2 , in which the percentage of sour and bitter responses to $\mathrm{HCl}$ and to quinine sulfate are both relatively high. Other insensitivities or confusions appeared to be distributed essentially randomly with this sample size.

Békésy's recent support for the existence of the four basic taste qualities and receptors spectfic to them (Békésy, 1964), and the fact that the sourbitter quality confusion cannot be corrected by an informative procedure, suggest that this confusion is probably primarily physlological in origin. It may be that this confusion is a gustatory analogue of abnormal color vision.

\section{noferuaces}

Bekesy, G. von Sweetness produced electrically on the tongue and its relation to taste theories. J. cppl. Physiol. 1964, 19, 11051113.

Bekesy, G. von Taste theories and the chemical stimulation of single papillae. J. appl. Physiol., 1966, 21, 1-9.

Dzendolet, E., \& Meiselman, H. L. Gustatory quality changes as a function of solution concentration. Percept. \& Psychophys., $1967,2,29-33$.

Fischer, R., Griftin, F. \& Rockey, M. A. Gustatory chemoreception in man: multidisciplinary aspects and perspectives. Perspect. Biol. \& Med., 1966, 9, 549-577.

McBumey, D. H., \& Ptaftmann, C. Gustatory adaptation to saliva and sodium chloride. J. exp. Psychol., 1963, 65, 523-529.

Panghom, R. M. Discussion of "Interactions of suprathreshold taste stimulf." in M. R. Kare \& B. P. Halpern (Eds.), Phy siological and behavioral aspects of taste. Chicago: University of Chicago Press, 1961. P. 72.

Pfafmann, C. The sense of taste. In J. Fieid (Ed.), Handbook of physiology. Neurophysiology. Vol. 1. Washington, D. C.: Ametican Physiological Society, 1959.

Pilgrim, F. J. Interactions of suprathreshold taste stimuli. In M. R. Kare \& B. P. Halpern (Eds.), Physiological and behavioral aspects of taste. Chicago: University of Chicago Press, 1961. Pp. 66-78.

(Accepted for publication June 27, 1967.) 